\title{
Laser Photochemistry and Transient Raman Spectroscopy of Silyl-Substituted Fischer-Type Carbene Complexes
}

\author{
A. Denise Rooney, ${ }^{\dagger, \ddagger}$ John J. McGarvey,, ${ }^{, \dagger}$ Keith C. Gordon, ${ }^{\dagger, \$}$ \\ Ruth-Anne McNicholl, ${ }^{\dagger}$ Ulrich Schubert, ${ }^{\perp}$ and Wolfgang Hepp $\perp$ \\ School of Chemistry, Queen's University of Belfast, Belfast BT9 5AG, Northern Ireland, \\ and Institut fur Anorgansiche Chemie der Universitat, D-8700 Würzburg, Germany
}

Received October 16, 1992

\begin{abstract}
Pulsed laser irradiation of the silyl-substituted carbene complexes $(\mathrm{CO})_{5} \mathrm{~W}=\mathrm{C}(\mathrm{XR}) \mathrm{SiPh}_{3}$ $\left(\mathrm{XR}=\mathrm{NC}_{4} \mathrm{H}_{8}(1) ;=\mathrm{OEt}(2)\right)$ in various solvents has been investigated using transient absorbance and time-resolved resonance Raman scattering as monitoring techniques. Irradiation of (1) in noncoordinating or weakly-coordinating solvents at $355 \mathrm{~nm}$ within the ligand field absorption band results in the rapid formation, within the laser pulse duration, of a permanent photoproduct. Saturation of the irradiated solution with $\mathrm{CO}$ results in regeneration of the starting complex 1. IR and Raman spectral data suggest that the photoproduct is the internally stabilized 16electron species $(\mathrm{CO})_{4} \mathrm{~W}=\mathrm{C}\left(\mathrm{NC}_{4} \mathrm{H}_{8}\right) \mathrm{SiPh}_{3}$. The observations are discussed in relation to the previously reported formation of the same 16-electron species by thermolysis of 1 . When the irradiation is carried out in $\mathrm{CH}_{3} \mathrm{CN}$ as solvent, $\mathrm{UV}$-visible evidence suggests formation of the photosubstituted species $(\mathrm{CO})_{4}\left(\mathrm{CH}_{3} \mathrm{CN}\right) \mathrm{W}=\mathrm{C}\left(\mathrm{NC}_{4} \mathrm{H}_{8}\right) \mathrm{SiPh}_{3}$. No photoactivity, either transient or permanent, is seen in any solvent when the irradiation is carried out at $416 \mathrm{~nm}$, a wavelength which falls within the MLCT absorption region of 1 . When the ethoxy-substituted carbene complex 2 is irradiated in either the LF or MLCT absorption regions a transient species forms rapidly, within the laser pulse duration, and decays on a time scale of several $\mu \mathrm{s}$, with a lifetime dependent on solvent polarity but independent of $\mathrm{CO}$ concentration in solution. Time-resolved resonance Raman studies in which the sample is photolyzed at $355 \mathrm{~nm}$ and probed by means of a delayed pulse at $406 \mathrm{~nm}$ show the formation and decay of a transient consistent with the flash photolysis results. The data are interpreted in terms of photoinduced anti-syn isomerization of 2 about the $\mathrm{C}_{\text {carbene }}-\mathrm{O}$ bond.
\end{abstract}

\section{Introduction}

Organometallic photochemistry and spectroscopy including time-resolved studies are areas of considerable and growing interest, with metal carbonyls and mixedligand carbonyls receiving the most attention. ${ }^{1}$ Metalcarbene complexes have also been studied, both in solution ${ }^{2}$ and in low-temperature matrices ${ }^{3}$ and were the subject of the first reported ${ }^{4}$ application of time-resolved resonance Raman spectroscopy to the study of photogenerated transients in an organometallic complex. The Fischer carbene complex, $(\mathrm{CO})_{5} \mathrm{~W}=\mathrm{C}\left(\mathrm{OCH}_{3}\right) \mathrm{C}_{6} \mathrm{H}_{5}$, has absorption bands with maxima near 350 and $375 \mathrm{~nm}$, attributable to ligand field and MLCT transitions, respectively. In a

\footnotetext{
† Queen's University of Belfast.

† Present address: Department of Chemistry, University of York.

\$ Present address: Department of Chemistry, University of Otago, Dunedin, New Zealand.

$\perp$ Institut fur Anorganische Chemie der Universitat.

(1) Brookhart, M.; Chandler, W.; Kessler, R. J. ; Lin, Y.; Pienta, N. J.; Santini, C. C.; Hall, C.; Perutz, R. N.; Timney, J. A. J. Am. Chem. Soc. 1992, 114, 3802 and references cited therein.

(2) (a) Fisher, E. O.; Fischer, H. Chem. Ber. 1974, 107, 657. (b) Hermann, W. A. Chem. Ber. 1975, 108, 486. (c) Rieke, R. D.; Kojihana, H.; Ofele, K. J.Am. Chem. Soc. 1976, 98,6735. (d) Dahlgren, R. M.; Zink, J.I. Inorg. Chem. 1977, 16, 3154. (e) Fischer, E. O. Besl, G. J. Organomet. Chem. 1978, 157, C33. (f) Wright, R. E.; Vogler, A. J. Organomet. Chem. 1978, 160, 197. (g) Edwards, B. H.; Rausch, M. D. J. Organomet. Chem. 1981, 210, 91. (h) McCormick, F. B.; Kiel, W. A.; Gladgyz, J. A. Organometallics 1982, 1, 405. (i) Casey, C. P.; Shusterman, A. J.; Vollendorf, N. W.; Haller, K. J. J. Am. Chem. Soc. 1982, 104, 2417. (j) Foley, H. C.; Strubinger, L. M.; Targos, T. S.; Geoffroy, G. L. J. Am Chem. Soc. 1983, 105, 3064. (k) Fong, L. K.; Cooper, N. J. J. Am. Chem. Soc. 1984, 106, 2595 .
}

(3) Servaas, P. C.; Stufkens, D. J.; Oskam, A. J. Organomet. Chem. $1990,390,61$

(4) Bell, S. E. J.; Gordon, K. C.; McGarvey, J. J. J. Am. Chem. Soc. $1988,110,3107$. matrix at $10 \mathrm{~K}$ the most significant primary process following irradiation ${ }^{3}$ into either the LF or MLCT bands is anti $\rightleftharpoons$ syn isomerization about the carbene $\mathrm{C}-\mathrm{O}$ bond.<smiles>C=C(Oc1ccccc1)C(OC)=[N+]([O-])C(=O)OC</smiles>

Upon irradiation into the LF band alone, secondary photodissociation of $\mathrm{CO}$ is observed, in addition to isomerization. A closely related but much less widely studied group of carbene complexes are those with silyl substituents. ${ }^{5}$ The thermal reactivity of species of the type $(\mathrm{CO})_{5} \mathrm{WC}(\mathrm{XR}) \mathrm{SiPh}_{3}$ has been investigated. ${ }^{5,6}$ When $\mathrm{XR}=\mathrm{NC}_{4} \mathrm{H}_{8}$ (1), thermal dissociation of $\mathrm{CO}$ is observed ${ }^{6 \mathrm{c}}$ to give the 16-electron product, $(\mathrm{CO})_{4} \mathrm{WC}\left(\mathrm{NC}_{4} \mathrm{H}_{3}\right) \mathrm{SiPh}_{3}$. This product is stabilized by a relatively minor change of conformation so that one of the phenyl rings of the $\mathrm{SiPh}_{3}$ group can act as a screen for the vacant site at the tungsten center. In constrast, when $\mathrm{XR}=\mathrm{OC}_{2} \mathrm{H}_{5}$ (2), no 16-electron products are observed upon thermolysis. Several major species are formed, among them $\mathrm{HSiPh}_{3}$, ethene, $\mathrm{EtSiPh}_{3}$, and $\mathrm{Ph}_{3} \mathrm{SiC}(\mathrm{O}) \mathrm{Et}$. The photoreactivity of these systems has not previously been studied. The present paper reports

(5) (a) Schubert, U. J. Organomet. Chem. 1988, 358, 215. (b) Hepp, W.; Schubert, U. J. Organomet. Chem. 1987, 321, 317.

(6) (a) Schubert, U.; Hepp, W.; Muller, J. Organometallics 1986, 5, 173. (b) Schubert, U.; Hornig, H. J. Organomet. Chem. 1987, 335, 307. (c) Hepp, W.; Schubert, U. J. Organomet. Chem. 1990, 385, 221. 


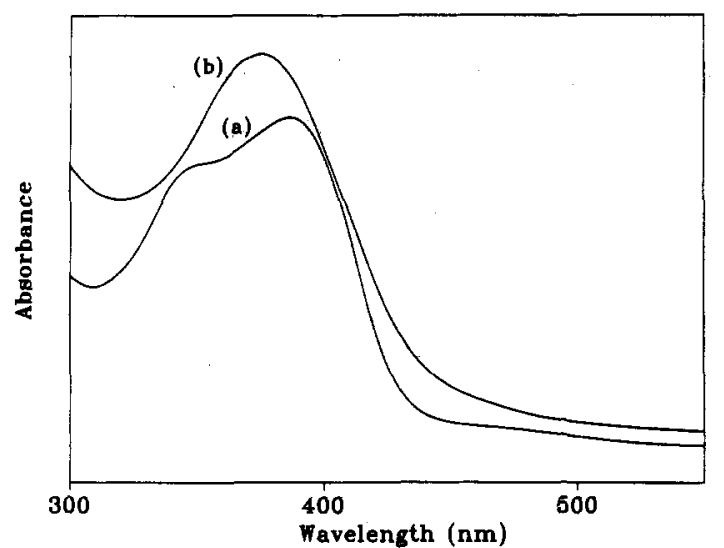

Figure 1. Spectral changes observed in $(\mathrm{CO})_{5} \mathrm{~W}=\mathrm{C}\left(\mathrm{NC}_{4} \mathrm{H}_{8}\right)$ $\mathrm{SiPh}_{3}$ upon irradiation in pentane solution at $354.7 \mathrm{~nm}$. Trace a: spectrum prior to photolysis. Trace b: spectrum recorded after pulsed irradiation at $354.7 \mathrm{~nm}$ for $3 \mathrm{~min}$ (pulse energy ca. $5 \mathrm{~mJ}$; rep rate $10 \mathrm{~Hz}$ ). Spectra have been displaced vertically for convenience of presentation.

our findings from an investigation of 1 and 2 by laser flash photolysis coupled with time-resolved UV-visible and resonance Raman spectroscopy.

\section{Experimental Section}

Flash photolysis and transient resonance Raman (RR) studies were carried out using the apparatus described previously, ${ }^{7}$ based upon a pulsed Nd/YAG laser. Two-color time-resolved RR experiments were conducted at the Central Laser Facility, Rutherford Appleton Laboratory (RAL), using excimer and excimer-pumped dye lasers as pump and probe sources respectively.

Compounds were prepared as described elsewhere. ${ }^{6}$ For the flash photolysis experiments involving spectrophotometric monitoring in the UV-visible range degassed or argon-purged samples in 1-cm fluorimeter cells were used. For the time-resolved Raman measurements the argon-purged samples were circulated through a quartz capillary (ca. 1-mm i.d.) at a rate which ensured that each pump/probe pulse combination encountered a fresh volume of sample, thus minimizing sample decomposition in the laser beam.

\section{Results}

(a) Flash Photolysis. (CO) ${ }_{5} \mathrm{WC}\left(\mathrm{NC}_{4} \mathrm{H}_{8}\right) \mathrm{SiPh}_{3}$ (1). Complex 1 is a pale yellow solid with a ground-state electronic absorption spectrum exhibiting two bands located at 354 and $380 \mathrm{~nm}$ in dichloromethane solution. Excited-state absorption measurements, following pulsed excitation at $355 \mathrm{~nm}$ of a solution of 1 in pentane resulted in a rapid, instrument-response-time-limited change in the absorbance which was permanent over the range $350-$ $500 \mathrm{~nm}$. The observed spectral changes are shown in Figure 1. The ground-state MLCT absorption band of 1 undergoes a small blue shift while the adjacent LF band near $350 \mathrm{~nm}$ gradually decreases in intensity. When $\mathrm{CO}$ is bubbled through the solution the parent complex is regenerated and the original spectrum is restored. No detectable photoreaction occurred when the irradiation wavelength was altered to $416 \mathrm{~nm}$.

When the 355-nm irradiation experiment was repeated in $\mathrm{CH}_{3} \mathrm{CN}$ instead of pentane, a similar shift to the blue

(7) (a) Bell, S. E. J.; Gordon, K. C.; McGarvey, J. J. Inorg. Chem. 1988, 27, 4003. (b) Bell, S. E. J.; Gordon, K. C.; McGarvey, J. J. J. Raman. Spectrosc. $1989,20,105$.

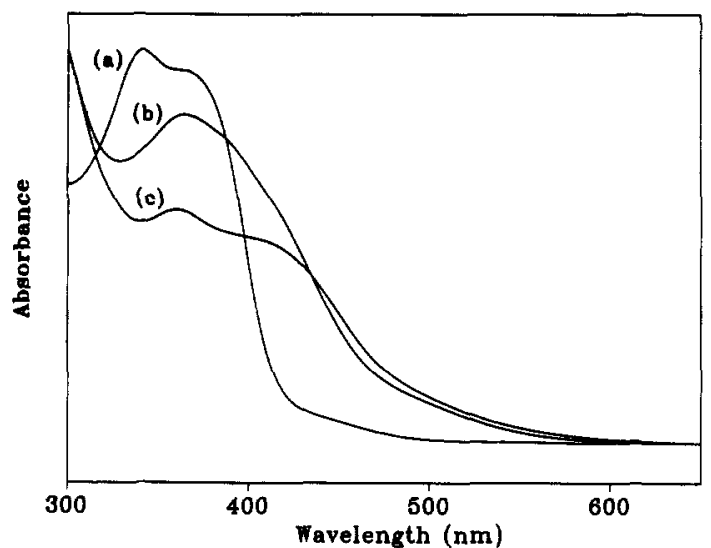

Figure 2. Spectral changes following pulsed irradiation at $354.7 \mathrm{~nm}$ of $(\mathrm{CO})_{5} \mathrm{~W}=\mathrm{C}\left(\mathrm{NC}_{4} \mathrm{H}_{8}\right) \mathrm{SiPh}_{3}$ in $\mathrm{Ar}$-purged $\mathrm{CH}_{3} \mathrm{CN}$ solution: (a) before irradiation; (b) after $2 \mathrm{~min}$ of irradiation; (c) after $4 \mathrm{~min}$ of irradiation (ca. $5 \mathrm{~mJ}$ pulse energy, rep rate $10 \mathrm{~Hz}$ ). Spectra have been displaced vertically for convenience of presentation.

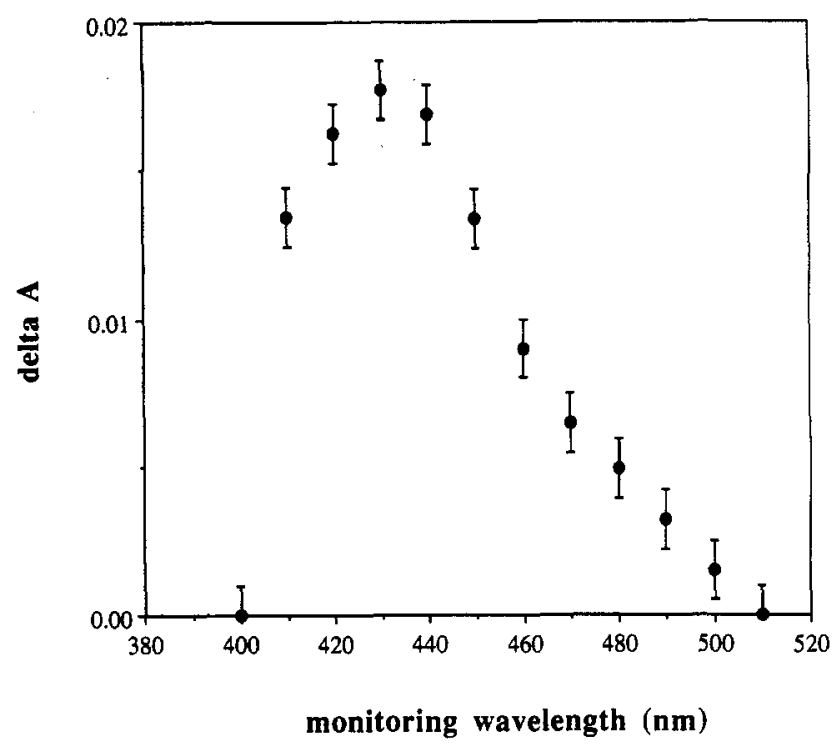

Figure 3. Transient absorbance difference spectrum recorded following flash photolysis of 2 at $354.7 \mathrm{~nm}$ in pentane solution (solution concentration ca. $10^{-3} \mathrm{~mol} \mathrm{dm}^{-3}$, pulse energy $10 \mathrm{~mJ}$; error bars refer to an estimated $10 \%$ error).

Table I. Influence of Solvent on Lifetimes of Transients Generated by Flash Photolysis of $(\mathrm{CO})_{3} \mathrm{WC}(\mathrm{OEt}) \mathrm{SiPh}_{3}$ at $355 \mathrm{~nm}$

\begin{tabular}{llll}
\hline solvent & lifetime ${ }^{a} / \mu \mathrm{s}$ & solvent & lifetime $/ \mu \mathrm{s}$ \\
\hline $\mathrm{CH}_{2} \mathrm{Cl}_{2}$ & $7.0 \pm 0.2^{b, c}$ & $\mathrm{C}_{6} \mathrm{H}_{12}$ & $2.5 \pm 0.2$ \\
$\mathrm{n}-\mathrm{C}_{5} \mathrm{H}_{12}$ & $2.3 \pm 0.4$ & $\mathrm{CHCl}_{3}$ & $4.6 \pm 0.2^{b, d}$ \\
$\mathrm{CH}_{3} \mathrm{CN}$ & $5.5 \pm 0.5$ & &
\end{tabular}

${ }^{a}$ Ar-saturated solutions at $21^{\circ} \mathrm{C} .{ }^{b}$ Values unchanged in $\mathrm{CO}$-saturated solutions. ${ }^{c}$ Lifetimes also measured in this solvent at the temperatures (K) indicated: $14.7 \pm 0.5(281), 20.9 \pm 0.7$ (276), $33.6 \pm 3.0$ (269). ${ }^{d}$ Solution temp, $24^{\circ} \mathrm{C}$.

of the MLCT band was again observed, and in addition the growth of a new band occurred near $420 \mathrm{~nm}$. The spectral changes are shown in Figure 2.

$(\mathrm{CO})_{5} \mathrm{WC}(\mathrm{OEt}) \mathrm{SiPh}_{3}(2)$. Complex 2 is a dark red solid, the electronic absorption spectrum in dichloromethane exhibiting two bands at 358 and $398 \mathrm{~nm}$. Markedly different flash photolysis behavior compared to 1 was observed for complex 2 . Irradiation at $355 \mathrm{~nm}$ in pentane caused a rapid, instrument response-limited 

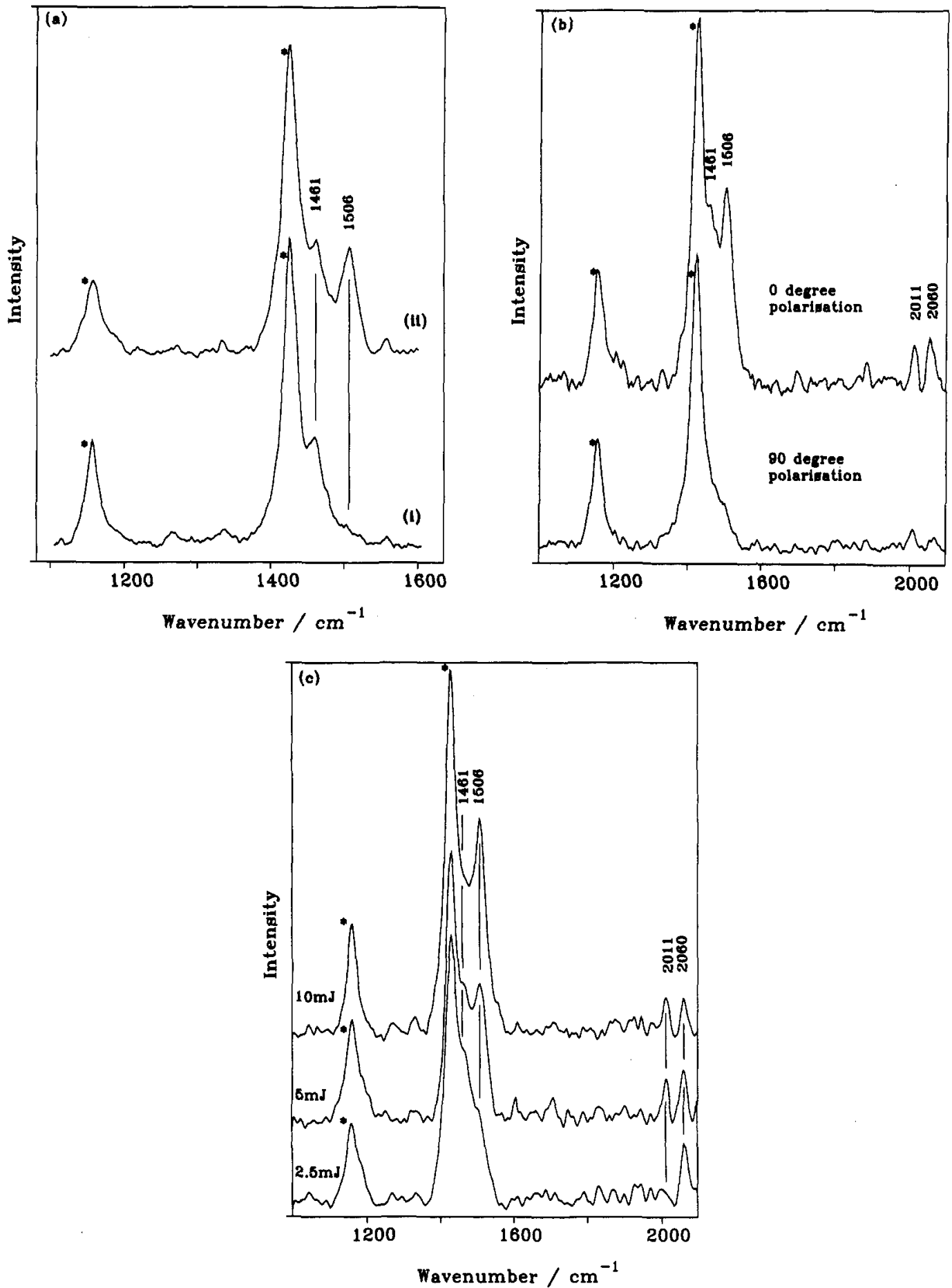

Figure 4. Changes in Raman spectra observed following pulsed irradiation of $(\mathrm{CO})_{5} \mathrm{~W}=\mathrm{C}\left(\mathrm{NC}_{4} \mathrm{H}_{8}\right) \mathrm{SiPh}_{3}$ in $\mathrm{CH}_{2} \mathrm{Cl}_{2}$ (ca. 10-3 mol $\mathrm{dm}^{-3}$ ). (a) Trace i: spectrum recorded at $\lambda_{\text {exc }}=416 \mathrm{~nm}$ (pulse energy ca. $4 \mathrm{~mJ}$, spectra accumulated for 6 min). Trace ii: spectrum recorded at $\lambda_{\text {exc }}=354.7 \mathrm{~nm}$ (pulse energy ca. $4 \mathrm{~mJ}$, spectra accumulated for $10 \mathrm{~min}$ ). (b) Polarization study of a sample similar to that used to record trace ii above, $\lambda_{e x c}=354.7 \mathrm{~nm}$. (c) Influence of laser energy on grow-in of features at 1506 and $2011 \mathrm{~cm}^{-1}$ due to permanent photoproduct, $\lambda_{e x c}=354.7 \mathrm{~nm}$. Spectral accumulation time was $10 \mathrm{~min}$ on fresh sample at each energy $(*=$ solvent features).

rise in absorbance monitored at several wavelengths in the range $340-500 \mathrm{~nm}$, followed by exponential decay to the preflash absorbance level. The transient absorbance difference $(\Delta A)$ spectrum is shown in Figure 3 and exhibits a red shift from the absorption spectrum of the parent complex. Saturation of the solution with $\mathrm{CO}$ had no effect on the transient lifetime. However, the lifetime did vary with temperature and solvent, as shown by the data in Table I. In contrast to the situation with 1 , no permanent photoproduct was observed following irradiation of 2 in pentane or $\mathrm{CH}_{3} \mathrm{CN}$ at either 355 or $416 \mathrm{~nm}$. (b) Resonance Raman Spectroscopy. The resonance Raman spectrum of 1 in $\mathrm{CH}_{2} \mathrm{Cl}_{2}$ generated by pulsed excitation at $416 \mathrm{~nm}$ is shown in Figure 4a, trace i. At 416 $\mathrm{nm}$ no photoproduct is created and the Raman spectrum observed is that of the parent complex 1 . The main spectral features are bands at $1461 \mathrm{~cm}^{-1}$ and in the carbonyl region near $2060 \mathrm{~cm}^{-1}$. Attempts to generate the ground-state resonance Raman spectrum of 1 using $\lambda_{\text {exc }}=354.7 \mathrm{~nm}$ invariably resulted in a spectrum with new features (trace ii), at 1506 and $2011 \mathrm{~cm}^{-1}$. Figure $4 \mathrm{c}$ shows the effect on solutions of 1 of varying the $354.7-\mathrm{nm}$ excitation energy. 


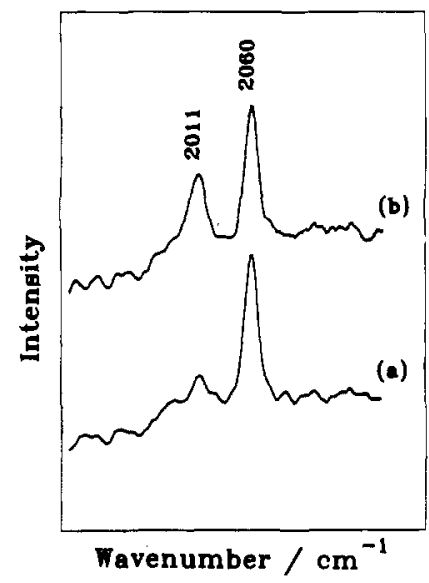

Figure 5. Influence of $\mathrm{CW}$ irradiation ( $\mathrm{Ar}^{+}$laser) at 363.8 $\mathrm{nm}$ on solution of 1 in $\mathrm{CH}_{2} \mathrm{Cl}_{2}$ (ca. $10^{-3} \mathrm{~mol} \mathrm{dm}^{-3}$ ). Trace a: spectrum recorded without prior irradiation. Trace b: same sample irradiated for $20 \mathrm{~min}$ at $363.8 \mathrm{~nm}$ prior to recording Raman spectrum (laser power at sample ca. $20 \mathrm{~mW}$ ).

Table II. Raman and IR ${ }^{b}$ Bands $\left(\mathrm{cm}^{-1}\right)$ for

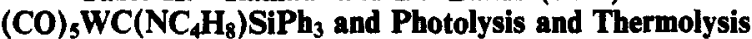
Products

\begin{tabular}{|c|c|c|}
\hline & Raman & IR \\
\hline$(\mathrm{CO})_{5} \mathrm{WC}\left(\mathrm{NC}_{4} \mathrm{H}_{8}\right) \mathrm{SiPh}_{3}(\mathbf{1})$ & 2060,1461 & $\begin{array}{l}2055,1968,1931,1928, \\
1921\end{array}$ \\
\hline $\begin{array}{l}\text { photoproduct from } \\
\text { irradiation of } 1 \\
\text { at } 355 \mathrm{~nm}\end{array}$ & 2011,1506 & $2015,1923,1909,1856$ \\
\hline $\begin{array}{l}\text { product from } \\
\text { thermolysis' of } 1\end{array}$ & & $2010,1925,1911,1859$ \\
\hline
\end{tabular}

At higher light intensities, where photoproduct formation is more rapid, the 1506 and $2011 \mathrm{~cm}^{-1}$ bands are stronger. Fresh solutions of 1 were used to record each of the three spectra shown in Figure 4c. Both the 1506 and $2011 \mathrm{~cm}^{-1}$ features are polarized (Figure $4 \mathrm{~b}$ ). Although the spectrum excited at $416 \mathrm{~nm}$ (Figure 4a, trace i) showed only groundstate features, bands at 1506 and $2011 \mathrm{~cm}^{-1}$ did appear in the spectrum (not shown here) generated at this same $\lambda_{\text {exc }}$ after the sample had been irradiated at $354.7 \mathrm{~nm}$. The same frequency changes are seen at $\lambda_{\text {exc }}=363.8 \mathrm{~nm}$ (CW excitation using an $\mathrm{Ar}^{+}$laser) after the sample had been irradiated at this wavelength for several minutes prior to recording the Raman spectrum. The effect is demonstrated in Figure 5 which shows the influence of $363.8-\mathrm{nm}$ irradiation on the Raman spectra in the carbonyl region. Trace a shows the spectrum recorded immediately upon exposure to 363.8-nm radiation, while for trace $b$, in which the $2011 \mathrm{~cm}^{-1} \mathrm{CO}$ band is evident, the sample was irradiated for $20 \mathrm{~min}$ at $363.8 \mathrm{~nm}$ prior to recording the Raman spectrum.

The above findings are summarized in Table II which includes the $I R$ spectra data for complex 1 recorded before and after irradiation at $363.8 \mathrm{~nm}$. Also shown for comparison are the IR data ${ }^{6 c}$ for the thermally generated 16-electron species, $(\mathrm{CO})_{4} \mathrm{~W}=\mathrm{C}\left(\mathrm{NC}_{4} \mathrm{H}_{8}\right) \mathrm{SiPh}_{3}$.

The Raman spectra recorded for the OEt-substituted complex 2 are different from those which characterize 1. The results are summarized in Figure 6. The spectral range from ca. 300 to $2100 \mathrm{~cm}^{-1}$ was scanned, but the main features which appear in the ground-state spectrum excited at $363.8 \mathrm{~nm}$ are two moderately intense bands at 798 and $875 \mathrm{~cm}^{-1}$. A single color pump and probe study employing pulsed excitation at $416 \mathrm{~nm}$ results in the appearance of an additional transient feature at $782 \mathrm{~cm}^{-1}$ as shown in trace $b$ of Figure 6 . In this experiment, the effective delay between pump and probe is the pulse duration, i.e., ca. 8 ns. A complete two-color time-resolved resonance Raman $\left(\mathrm{TR}^{3}\right)$ study on 2 was also carried out, using a pump wavelength of $351 \mathrm{~nm}$ and a probe wavelength set at 406 $\mathrm{nm}$. The results are shown in Figure 7. The $782 \mathrm{~cm}^{-1}$ feature is present at short pump-probe delays but decays over a time scale of a few $\mu$ s. The findings parallel the flash photolysis studies referred to above on 2 in the same solvent $\left(\mathrm{CH}_{2} \mathrm{Cl}_{2}\right)$ where a transient lifetime of $7 \mu \mathrm{s}$ was recorded.

\section{Discussion}

The shift in $\lambda_{\max }$ (in pentane) of the longest wavelength band in the ground electronic state absorption spectra, from $380 \mathrm{~nm}$ in 1 to $398 \mathrm{~nm}$ in 2, suggests that the lowest excited state in these complexes is MLCT in nature since the shift is in line with the degree of stabilization of such a state in metal-carbene complexes which would be expected ${ }^{8}$ upon replacement of nitrogen $\left(\mathrm{NC}_{4} \mathrm{H}_{8}\right.$ in 1$)$ by the less electron-donating oxygen atom (OEt in 2). The bands at slightly higher energy ( 354 and $358 \mathrm{~nm}$ in 1 and 2 , respectively) are attributed to LF transitions.

The IR and Raman spectral data summarized in Table II indicate that the permanent photoproduct formed when complex 1 is irradiated at $355 \mathrm{~nm}$ is identical to the 16electron CO-loss species generated by thermolysis of 1 . Hence, the results of the irradiation experiment is also consistent with the assignment of this band as LF in nature since excitation here would be expected to result in $\mathrm{CO}$ loss as observed. On the basis of the established X-ray structure reported ${ }^{6 \mathrm{c}}$ for the thermolysis product from the analogous complex, $(\mathrm{CO})_{5} \mathrm{WC}\left(\mathrm{NC}_{5} \mathrm{H}_{10}\right) \mathrm{SiPh}_{3}$, the permanent photoproduct from 1 is assigned to a 16-electron complex in which a phenyl ring of the $\mathrm{SiPh}_{3}$ group screens the vacant site on the tungsten. The fact that 1 and the analogous complexes with $\mathrm{NR}_{2}=\mathrm{NC}_{5} \mathrm{H}_{10}$ and $\mathrm{NR}_{2}=$ NEtMe behave in identical fashion upon thermolysis ${ }^{6 c}$ supports our assignment. It is significant that no photoproduct is formed when 1 is irradiated at $416 \mathrm{~nm}$. This is in line with the band assignments proposed above since $416 \mathrm{~nm}$ lies within the MLCT transition whereas CO loss is associated with population of the higher energy LF state. The blue shift to $356 \mathrm{~nm}$ of the MLCT band at $386 \mathrm{~nm}$ and the growth of a new band at $420 \mathrm{~nm}$ when 1 is irradiated in $\mathrm{CH}_{3} \mathrm{CN}$ indicate the formation of a photosubstitution product in which $\mathrm{CH}_{3} \mathrm{CN}$ occupies the site vacated by $\mathrm{CO}$. This is analogous to the behavior previously noted ${ }^{2 j}$ for the Fischer carbene complex. The band at $2011 \mathrm{~cm}^{-1}$ characteristic of the 16-electron species appears both in the Raman and IR spectra. An equivalent band (ca. 2017 $\mathrm{cm}^{-1}$ ) also appears ${ }^{2 \mathrm{i}}$ in the IR spectra of cis- $(\mathrm{CO})_{4} \mathrm{LW}=\mathrm{C}$ $\left(O^{\prime}\right) R$ where the ligand $L$ is in a cis arrangement with respect to the $W-C_{\text {carbene }}$ bond. The band is assigned ${ }^{2 j}$ to a $\nu_{\mathrm{CO}}$ mode of species $\mathrm{a}_{1}$ in the approximate local symmetry of $C_{2 v}$ assumed for the cis complex. The 16-electron product from thermolysis of $(\mathrm{CO})_{5} \mathrm{WC}\left(\mathrm{NC}_{5} \mathrm{H}_{10}\right) \mathrm{SiPh}_{3}$, the analogue of 1 , also shows ${ }^{6 c}$ a cis arrangement of the $\mathrm{W}-\mathrm{C}_{\text {carbene }}$ bond with respect to the phenyl ring of the $\mathrm{SiPh}_{3}$ group which screens the vacant site at the tungsten.

(8) Hoffmann, P. In Transition Metal Carbene Complexes; Fischer, H., Ed.; Verlag Chemie: Weinheim, 1983. 
The fact that the $2011 \mathrm{~cm}^{-1}$ band in the Raman spectrum of 1 (Figure $4 \mathrm{~b}$ ) is polarized is consistent with its assignment to a $\mathrm{CO}$ mode of species $\mathrm{a}_{1}$.

The behavior of complex 2 upon irradiation contrasts markedly with the above. No permanent photoproduct is formed upon irradiation at $355 \mathrm{~nm}$ in pentane, and the additional irradiation studies at this wavelength in acetonitrile exhibited no evidence for $\mathrm{CO}$ photosubstitution. This suggests that the quantum yield $\phi$ for $\mathrm{CO}$ loss in this complex at an irradiation wavelength of $355 \mathrm{~nm}$ is very low. The transient species which does form following irradiation at either $355 \mathrm{~nm}$ or $416 \mathrm{~nm}$ decays with a lifetime independent of [CO] in solution, a further indication that $\mathrm{CO}$ photodissociation is not involved. The dependence of transient lifetime on solvent is reminiscent of that observed ${ }^{4}$ for the Fischer complex $(\mathrm{CO})_{5} \mathrm{~W}=\mathrm{C}$ $\left(\mathrm{OCH}_{3}\right) \mathrm{Ph}$ for which it has recently been suggested ${ }^{3}$ on the basis of irradiation studies in an inert gas matrix that the major process following irradiation in either the MLCT or LF absorption region is photoinduced isomerization to the syn form from the anti configuration of the ground electronic state:

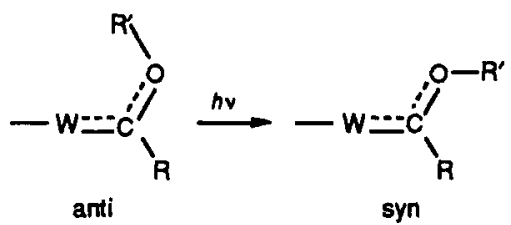

$\mathrm{X}$-ray crystallographic studies ${ }^{9}$ of the $\mathrm{Cr}$ analogue of 2 , $(\mathrm{CO})_{5} \mathrm{CrC}(\mathrm{OEt}) \mathrm{SiPh}_{3}$, show that it exists in the ground state largely as the anti-isomer. If we suppose that in 2 the anti isomer is likewise favored, as with the majority of carbene complexes of this type, then the transient formation and solvent-dependent decay observed when 2 is irradiated in the LF or MLCT absorption regions may be attributed to anti to syn photoisomerization by analogy with the Fischer complex. This conclusion is supported by the data in Table I showing the variation with temperature observed for the transient in $\mathrm{CH}_{2} \mathrm{Cl}_{2}$ solution. An Eyring plot of the data yields an approximate activation enthalpy of $42 \mathrm{~kJ} \mathrm{~mol}^{-1}$, similar to that measured ${ }^{10}$ for the Fischer complex in the same solvent. The photophysical picture proposed ${ }^{3}$ in the latter case envisages the isomerization to take place via the lowest lying triplet MLCT state, and it seems reasonable to conclude that the photoisomerization in 2 is also mediated by the corresponding lowest lying triplet state. If it is assumed that electric dipole transitions from either the anti or the higher energy syn isomers of 2 take place to equienergetic Franck Condon levels of this MLCT state, the red shift observed in the $\Delta A$ spectrum of the syn isomer (Figure 3 ) can be accounted for, and this in turn would be internally consistent with the attribution of the transient absorbance changes to the photoisomerization. A similar red shift noted ${ }^{11}$ in the $\Delta A$ spectrum associated with the corresponding anti to syn isomerization of the carbene complex $(\mathrm{CO})_{5} \mathrm{WC}(\mathrm{OMe}) \mathrm{Me}(3)$ may be explained in a like manner.

(9) Fischer, E. O.; Hollfelder, H.; Friedrich, P.; Kriessl, F. R.; Huttner, G. Chem. Ber. 1977, 110, 3467.

(10) Rooney, A. D. Ph.D. Thesis, Queen's University, Belfast, 1991

(11) This simple picture in which the MLCT state is reprsented by a symmetrical PE "curve" is evidently not applicable in the case of the Fischer complex, $(\mathrm{CO}){ }_{5} \mathrm{WC}(\mathrm{OMe}) \mathrm{Ph}$, where $\mathrm{a}$ blue shift ${ }^{10}$ is observed in the $\Delta A$ spectrum associated with photoisomerization. This point will be taken up elsewhere.

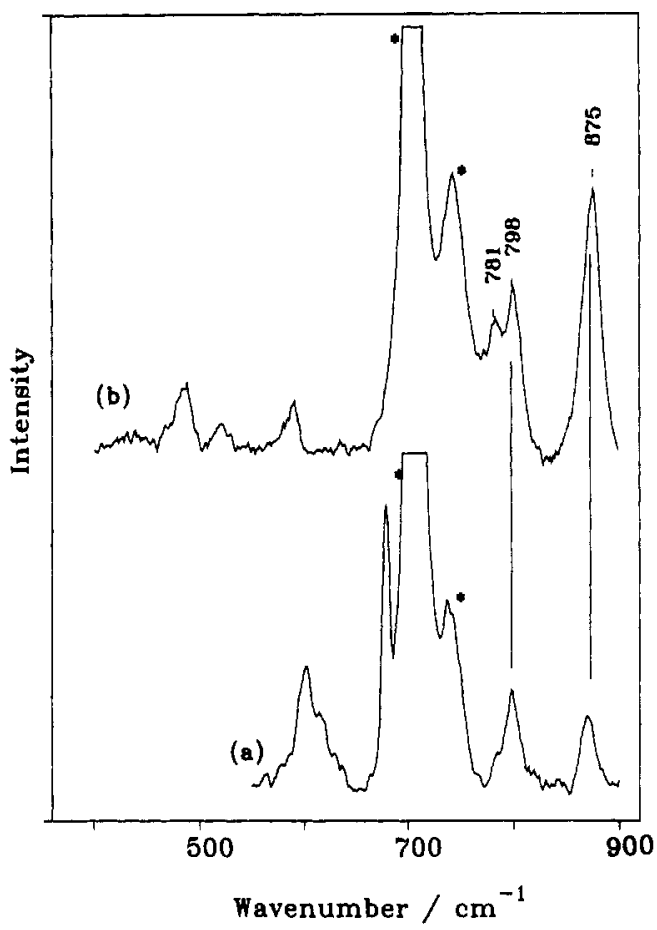

Figure 6. Raman spectra of $(\mathrm{CO})_{5} \mathrm{~W}=\mathrm{C}(\mathrm{OEt}) \mathrm{SiPh}_{3}$ recorded in $\mathrm{CH}_{2} \mathrm{Cl}_{2}$ : (a) $\mathrm{CW}$ excitation with $\mathrm{Ar}^{+}$laser, $\lambda_{\text {exc }}=363.8 \mathrm{~nm}$; (b) pulsed excitation at $\lambda_{\text {exc }}=416 \mathrm{~nm}$ (single color pump and probe experiment with effective pump-probe delay of ca. 8 ns) $(*=$ solvent features).

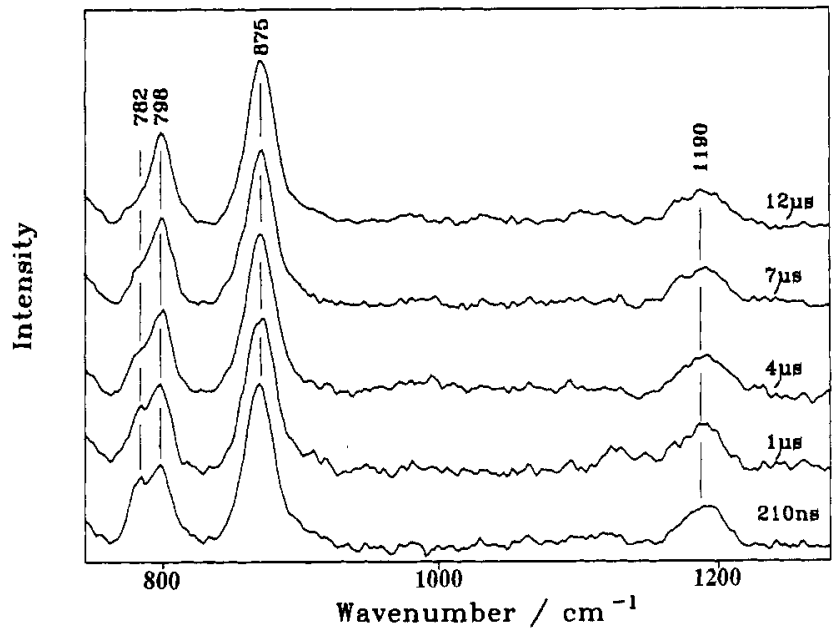

Figure 7. Two-color time-resolved resonance Raman study of $(\mathrm{CO})_{5} \mathrm{~W}=\mathrm{C}(\mathrm{OEt}) \mathrm{SiPh}_{3}$ in $\mathrm{CH}_{2} \mathrm{Cl}_{2}$ (ca. $10^{-3} \mathrm{~mol} \mathrm{dm}^{-3}$ ): Pump $\lambda 351 \mathrm{~nm}$; probe $\lambda 406 \mathrm{~nm}$ (probe pulse energy ca. 0.4 $\mathrm{mJ})$.

However, the transient $\triangle A$ decay time (in effect the lifetime of the syn isomer) measured in this case ${ }^{10}$ is at least 2 orders of magnitude longer than for complex 2 under investigation here. This may be largely a reflection of a greater degree of steric interaction between the OEt and bulky $\mathrm{SiPh}_{3}$ groups in 2 compared to that between the $\mathrm{OMe}$ and $\mathrm{Me}$ groups of 3 .

The results of the $T^{3}$ studies displayed in Figure 7 show that the feature at $782 \mathrm{~cm}^{-1}$ decays on the $\mu$ s time scale. This provides strong evidence that this feature is associated with the transient observed in the flash photolysis experiments and assigned to the syn isomer. The $782 \mathrm{~cm}^{-1}$ band is thus a convenient Raman signature for this isomer. No species have been detected in the transient Raman studies which could be attributed to $\mathrm{CO}$ 
loss, suggesting that $\phi$ for this process is very low, as already suggested by the flash photolysis studies. In the case of complex $1 \mathrm{CO}$ loss does occur and a permanent $\mathrm{CO}$ loss photoproduct is readily detectable.

The two systems therefore provide an interesting contrast in photochemical behavior. With 1, photoactivity in the form of $\mathrm{CO}$ photodissociation occurs only upon irradiation within the LF band. Irradiation within the MLCT region produces no detectable effect. In the case of complex 2 irradiation at wavelengths within either LF or MLCT absorption regions produces a transient species with $\mu$ s lifetime assigned to the syn isomer generated by photoisomerization of 2 about the $\mathrm{C}_{\text {carbene }}-\mathrm{O}$ bond followed by decay to the favored anti form of the ground state of the complex. The fact that photoisomerization also occurs upon irradiation in the LF region suggests efficient communication between the initially populated LF state and the lower lying MLCT state. Anti and syn isomers are not defined in complex 1 because of the symmetry of the $\mathrm{NC}_{4} \mathrm{H}_{8}$ group. In this context a complex such as $(\mathrm{CO})_{5}$ -
$\mathrm{WC}(\mathrm{NMeEt})\left(\mathrm{SiPh}_{3}\right)$ is worthy of investigation. It is already $\mathrm{known}^{5}$ to form a 16-electron CO loss species upon thermolysis, and it would therefore be interesting to see whether it can undergo both types of photoreaction, namely CO loss through population of a LF state and photoisomerization about the $\mathrm{C}_{\text {carbene }}-\mathrm{NMeEt}$ bond via the lowest MLCT state.

This preliminary study of the flash photolysis of silyl carbene complexes provides some illustration of the value of complementing conventional spectrophotometric detection with time-resolved resonance Raman spectroscopy in probing the photoreactions of these systems.

Acknowledgment. We thank the SERC for support (Grant GR/F42980) and The Department of Education (Northern Ireland) for the award of a research studentship to A.D.R. The assistance of Dr. A. W. Parker and S. Tavender with the TR $^{3}$ experiments at the Rutherford Laboratory is gratefully acknowledged.

OM920643Q 